\title{
Requirements Engineering for Organizational Transformation
}

\author{
Isabel Ramos \\ Departamento de Sistemas de Informação, Universidade do Minho, \\ 4800 Guimarães, Portugal \\ Daniel M. Berry ${ }^{1}$ \\ School of Computer Science, University of Waterloo, \\ Waterloo, ON, N2T 3G1, Canada \\ João Á. Carvalho \\ Departamento de Sistemas de Informação, Universidade do Minho, \\ 4800 Guimarães, Portugal
}

\begin{abstract}
Traditional approaches to requirements elicitation stress systematic and rational analysis and representation of organizational context and system requirements. This paper argues that the introduction of any computer-based system to an organization transforms the organization and changes the work patterns of the system's users in the organization. These changes interact with the users' values and beliefs and trigger emotional responses which are sometimes directed against the computerbased system and its proponents. The paper debunks myths about how smoothly such organizational transformations take place, describes case studies showing how organizational transformation really takes place, and introduces and confirms by case studies some guidelines for eliciting requirements and the relevant emotional issues for a computer-based system that is being introduced into an organization to change its work patterns.
\end{abstract}

$\overline{1}$ Daniel Berry's work was supported in part by a Canadian NSERC grant, NSERCRGPIN227055-00. 


\section{Introduction}

Originally, computer-based systems (CBSs), actually just programs, were introduced merely to automate existing manual tasks for collecting, processing, or distributing information. A program was used for speed up, for error reduction, or for both in existing clerical tasks without changing the basic processes in which these tasks were carried out. If the original task produced a report on paper, the automated version produced the same report, so that the automated task could be carried out, albeit faster and with fewer errors, in the original task's place.

However, as observed by Meir Lehman [57], the introduction of these CBSs began to affect the processes in which these automated tasks were embedded. Different and better processes were enabled by the automated tasks, even to the point of making the automated original tasks unnecessary, and even to the point of eliminating some peoples' jobs!

New peripheral devices were introduced that allowed the computer to sense and control more than just data, e.g., to help operate production lines and to help fly aircraft. These devices allowed the introduction of CBSs to change more and more processes and to fundamentally alter the way things are done in many real-world, man-made systems not at all related to computing. For example, originally, commercial systems evolved in the presence of only paper and carbon paper. Thus, creating multiple copies of a document, i.e., a form, containing all conceivably required information about a transaction became the way to make sure that all needed information were distributed rapidly and in parallel to all involved in the transaction. Even so, these data were usually accurate only to the day or more. With the advent of computing, the production of the multiple copies was automated, with the basic workflow, and in particular the distribution of the copies, unaltered. Still, the data were usually accurate only to the day or more.

Later, as new high-resolution screens and networks became available, it was suddenly observed by creative software engineers that it was no longer necessary to print and distribute multiple paper copies of all possible needed information. Instead, it sufficed to put a network of computers, each with a high-resolution screen, on the desks of all persons involved in all transactions, and to allow each to access directly precisely the information he or she needed for his or her part of the transaction at the time he or she needed it. These data would be accurate to the moment. It is totally unnecessary to make any paper copy of the information. Fully automated enterprise resource planning (ERP) [27] had become possible.

On one hand, the operation of a transaction has improved. The information 
needed for the transaction is distributed or made available for access instantly to all involved in the transaction. A person involved in the transaction looks up only the information that he or she needs. Recall that a traditional form contains all information that might conceivably be needed in a transaction. With immediate electronic access, if it is known that a rarely needed item is readily accessible, it is possible to forgo requesting this item during the filling of the electronic form, leaving it to be found if and when it is actually needed. Thus, the transaction is made more efficient.

On the other hand, there are some negative consequences. At the very least, because no paper copies are distributed, all those involved with the production, purchasing, distribution, and disposal of paper and printed reports find their jobs reduced and possibly eliminated.

The organization has been transformed. The introduction of any CBS has the potential to transform any organization into which it is introduced. In general, the introduction of CBSs has become a driver for innovative work practices and new models of management and organization [22]. Furthermore, each employee that used to get his or her information from a particular place on one copy of all possible needed information now needs to work online on a computer with a windowing system with a program that allows querying for the needed information, but in a language derived from predicate calculus. One or more of these employees could rebel against this job change because he or she hates computers, hates mathematics or anything reeking of it, or refuses to learn any newfangled way to do something that he or she has done for years in a perfectly good simple way! "If it ain't broke, don't fix it!" says the employee. Clearly, emotional issues are coming into play in the use of CBSs and the organizational transformations (OTs) they breed.

Despite that innovative, organization transforming CBSs are introduced with the laudable goals of improving organizational efficiency and effectiveness, reducing costs, improving individual and group performance, and even enabling individuals to work to their potentials, it is sometimes very difficult to get these CBSs to be used successfully and effectively [61,47,3]. Some people in some organizations resist the changes. They resist using the systems, misuse them, or reject them. As a result, the goals are not achieved, intended changes are poorly implemented, and development budgets and schedules are not respected. Misplaced, as opposed to normal, emotions, values, and beliefs are often offered as the causes of these problems [3,68]. M.B. Bergman, J.L. King and K. Lyytinen [3] observe (p. 168), "Indeed, policymakers will tend to see all problems as political, while engineers will tend to see the same problems as technical. Those on the policy side cannot see the technical implications of unresolved political issues, and those on the technical side are unaware that the political ecology is creating serious problems that will show up in the functional ecology." They go on to say (p. 169), "We believe that one source 
of opposition to explicit engagement of the political side of RE [requirements engineering] is the sense that politics is somehow in opposition to rationality. This is a misconception of the nature and role of politics. Political action embodies a vital form of rationality that is required to reach socially important decisions in conditions of incomplete information about the relationship between actions and outcomes."

Exacerbating these potential emotional problems is the fact that environments into which the CBSs are introduced are incredibly complex [13][3][63, pp. 212215][66, pp. 317-348][69, pp. 169-195]. Thus, it is next to impossible to predict the effect that the introduction of a new CBS will have on the organization and its users.

Now, let us consider the changing nature of requirements engineering ( $\mathrm{RE}$ ) for CBSs. Initially, RE needed to consider only the input-output behavior, i.e., the functionality, of programs. Certainly, nonfunctional issues, especially performance, were important too. If an automated task ended up taking too much time, space, or both, the task would not be effectively automated. As CBSs began to change the real-world systems in which they were embedded, $\mathrm{RE}$ needed to consider the effects of the changes, and in some cases, to predict and even alter likely effects. As CBSs began to transform organizations deploying them, RE needed to consider how the organization should be transformed and to project organizational-level requirements onto the requirements for the CBSs that were to effect these transformations. Finally as users' emotions began to affect how well, and even if, the deployed CBSs would be used in the transformed organizations, RE needed to consider emotional issues and to project them onto the requirements for the CBSs triggering the emotional responses.

This paper attempts to describe the roles of emotions and of closely related values and beliefs in determining acceptance of deployed organizationtransforming CBSs. It reports case studies in which emotions, values, and beliefs of users and other stakeholders inhibited the success of the deployment of at least the originally conceived CBS. It offers guidelines derived from these case studies for eliciting stakeholders' emotions, values, and beliefs along with the usual functional and nonfunctional requirements.

Accordingly, Section 2 reviews the concept of OT as both triggering and being triggered by the deployment of enabling CBSs. It discusses some of the rhetoric about the OT process and about organizations. It defines emotions, values, beliefs, and gives some examples of how they can impact the OT process. Finally, it considers whether the observed effects are just managerial problems. Section 3 introduces the idea that RE for CBSs deployed during OT must elicit emotional issues. It describes additions to any traditional RE process that allow elicitation of emotional issues that can be considered along with 
all other requirements in producing a requirements specification. Section 4 compares the suggested approach with other work. Section 5 summarizes the paper and suggests future work.

This paper is about deploying CBSs during OT. Since the most flexible component of a CBS is its software, we often talk about developing its software, when in fact we are really developing the whole CBS. In this paper, "software system" and "CBS" are used interchangeably. Moreover, the assumed domain for these CBSs is any CBS for which there is a mandated or de facto RE process prior to building, buying, enhancing, or deploying the CBS. Thus, the domain includes contracted, bespoke CBSs; configurable, off-the-shelf CBSs; and in-house CBSs.

\section{OT Supported by the Deployment of CBSs}

The Introduction observed that deployment of CBSs in an organization for the purpose of changing the organization's way of doing business causes OT and that any such OT can cause emotional problems among the CBSs' users in the organization. These emotional problems affect the use of the CBSs just as any other requirements problem. Consequently, to understand the full requirements of a CBS, it is essential to understand the OT that the CBS enables and the OT's effects on the organization and on the CBS users' emotions. Therefore, this section explores what is known about OT, organizations, and emotions, often from other disciplines, for clues on how to carry out the necessary RE.

Organizational transformation (OT) [69, p. 171] is the process of fundamentally changing an organization's processes in order to allow it to better meet new challenges. OT is usually accompanied by deployment of so-called enabling CBSs, such as ERP systems, that help automate the organizations new processes and that sometimes make these new processes possible. That is, the OT triggers or is triggered by the deployment of the enabling CBSs, and sometimes the causality is in both directions. Certainly, the OT and the enabling CBSs share many requirements, particularly the higher level ones. RE for either of them is effectively RE for both of them. Therefore, whenever this paper talks about OT, it is also implicitly talking about its enabling CBSs and whenever this paper talks about a CBS, it is also implicitly talking about the OT enabled by the CBS. The lengthy phrase "OT and the deployment of its enabling CBSs" is sometimes abbreviated by "OT and its CBSs". Closely aligned with this RE for OTs and their CBSs is business-process reengineering [41], the total redesign of a business's processes based on what is known about the business's organization, its goals, its users, and the enabling CBSs. 
An organization does OT and deployment of its enabling CBSs to achieve a variety of goals, often more than one:

- to increase its income,

- to improve its market penetration,

- to reduce its reaction time, and

- to reduce costs,

all of which allow it to better meet new challenges. Triggers for OT and deployment of its enabling CBSs include an organization's desires to:

- implement a new management or business model,

- adopt a new best practice,

- satisfy clients better,

- create a new internal or external image,

- promote a new social order,

- obey environmental rules,

- foster collaborative practices,

- etc.

to achieve one or more of the goals. Sometimes, OT is triggered as a consequence of internal political fights over organizational goals and desires.

\subsection{Rhetoric and Myth About Organizational Transformation}

According to several authors $[16,40,48,53,13,17]$, there is a myth about OT that is prevalent among those who would try to implement it. Many implementers see OT as a process that can be planned, managed, and controlled. According to these implementers, OT is a rational and controllable process that can be systematically implemented using well-tested methods and techniques to guide it. Consequently, OT can be made predictable, quick, and reasonably cheap. OT is best led by consulting firms that are experts in the field. OT is often directed to the organizational structure: goals and strategies, processes, tasks and procedures, formal communication channels, coordination and control of activities, work needs, and authority levels. Finally, OT is expected to have an impact on organizational practices and on political relations.

Resistance to transformation of meanings and practices is often expected. This resistance is seen as a problem to solve or minimize as soon as possible. Individuals are expected to adhere to values such as flexibility, creativity, collaboration, and continuous learning. They are expected to be motivated to immediately, effectively, and creatively use the delivered system.

Every planned OT is seen initially as positive. In the end, the OT may fail. 
Since the OT is often justified by economic or political reasons, the failure is considered critical to the organization. Thus, there must be blame for the failure. The failure is often blamed on the leaders of the failed process, the consulting firms that failed to implement it, or the individuals and groups that failed to change.

The requirements engineer involved in the development of the CBSs for the OT must be aware of these dynamics in order to help the organization avoid falling into them.

\subsection{Organizations as Separate and Collective Entities}

We tend to see an organization as a separate entity with its own goals, strategies, potentialities, and constraints. However, an organization is the people that bring it into existence [26]. Goals and strategies emerge from the sensemaking processes that continually reshape human action and interaction in the organization and with the environment. This understanding leads to two main insights:

(1) The idea of an organization being a separate entity with its own goals and strategies serves mainly management interests. Traditionally, management responsibilities involve the coordination and control of individual and subgroup efforts, in order to guarantee the economic, social, and political success of the organization [11][69, pp. 11-34][66, pp. 11-31]. The strategy is to limit emotions, interests, values, and beliefs that could reduce the probability of achieving the goals and to implement strategies that management has defined as the best for the organization [66][54, pp. 152-213].

(2) Each member of an organization has interests, beliefs, and, sometimes, values that may not be in tune with the organizational identity that, maybe, someone else is trying to solidify [69, pp. 157-158][71, pp. 2645][88, pp. 55-70]. Of course, this potential conflict is why participation in decision processes is so important a theme in the social sciences. Nevertheless, when consensus is not possible, there is the possibility of negotiation $[3,54,9,64,78]$. There is always the possibility of giving up some interests and beliefs in exchange for other advantages. The imposition of decisions by powerful individuals or groups should be the last resort. Any negotiation or imposed decision may lead to the emergence of negative emotions such as frustration, fear, anger, and depression. The emotions may appear on the surface, or they may be held in silence. They may have unpredictable consequences for the development of organizational identity and for organizational success. 
The organization is, then, a collective entity emerging from the interplay of diverse interests and perspectives. These interests and perspectives are rooted in individual and shared emotions, values, and beliefs. However, the requirements engineer must be aware of and seek out the various emotions, values, and beliefs as part of the normal viewpoint resolution [25].

\subsection{Emotions, Values and Beliefs}

It is useful to define the three concepts used to construct the core ideas in this paper (1) emotions, (2) values and beliefs, and (3) change.

\subsubsection{Emotions}

According to Damásio [18], there are three types of emotions,

(1) primary emotions,

(2) background emotions, and

(3) social emotions.

Primary emotions include joy, sadness, fear, anger, surprise, and aversion. Background emotions include the sensations of well being and malaise, calmness and tension, pain and pleasure, enthusiasm and depression. Social emotions include shame, jealousy, guilt, and pride.

Three aspects of emotions make them difficult to deal with in many situations, especially in a situation in which one might not even expect emotions to be factor, such as the deployment of new software:

- Even if learning processes and culture are responsible for different expressions of emotions and for attaching different social meanings to them, emotions are biologically determined. They depend on cerebral devices that are innate and founded in the long evolutionary history of life on Earth.

- The cerebral devices upon which emotions depend may be activated without awareness of the triggering stimulus or without the exercise of will.

- For an adult human being, few objects and events are emotionally neutral.

Due to the uncertainty and ambiguity that always accompany OT, OT often triggers emotions. Since emotions are, by definition, automatic responses developed through individual experiences, it can be expected that the diversity of reactions to OT is incompatible with an instrumental, quick, low-cost approach. Therefore, the RE for the CBS must be rooted in an understanding of the social context of the systems and of the emotions, views, and preferences of their stakeholders [36]. 
It is clear that we are talking implicitly in this paper about negative emotions, against or confounding the construction or deployment of the CBS at hand. If the emotions of all stakeholders were positive, in favor of construction and deployment of the CBS, then emotional issues will not figure much in the requirements. In this case, the RE process would proceed as a so-called normal one, focusing strictly on the standard functional and nonfunctional requirements of the algorithmics, the technology, and the economics of the CBS.

\subsubsection{Values and Beliefs}

Human values are socially constructed concepts of right and wrong that we use to judge the goodness or badness of concepts, objects, and actions and their outcomes [43]. The beliefs that a person holds about the reality in which he lives define for him the nature of that reality, his position in it, and the range of possible relationships to that reality and its parts [58].

OT concepts and practices often require changes in or abandoning cherished and long-held beliefs and values. An example illustrates this issue. Suppose that an organization has decreed that all of its word processing be done in Microsoft (MS) Windows. Suppose also that one employee, Joe dislikes MS Windows. Perhaps Joe dislikes even the Microsoft company, because he believes that it is monopolistic. No one can force Joe to like MS Windows. He can be forced to show some appearance of liking it, but then there is no transformation in his fundamental operating system preferences, and the forcing only increases his dislike for MS Windows. He could be brainwashed, but brainwashing would hardly be considered an enlightened technique. Joe may be convinced of the advantages of liking MS Windows, thus ensuring his motivation to cooperate with the transformation process. However, not even Joe can guarantee the transformation of his fundamental operating system preferences. Nevertheless, if Joe is motivated to cooperate there are, in effect, some strategies to improve the chances of a successful transformation:

- by constructing pleasant views of Joe's past and future involving MS Windows, e.g, of playing a pleasant game of solitaire or of participating in pleasant interactions via Windows Explorer, or

- by addressing the dislike of the software head on, i.e., finding out what Joe dislikes about MS Windows and then fixing the problem by modifying preferences or even modifying the software.

- by addressing the dislike of the company head on, i.e., trying to separate Joe's views about the company from his view of the software or by trying to show some redeeming features of the company.

Thus, an OT process must plan on spending resources to improve the chances 
of making the process a success [63] (pp. 214-234), and it will be the job of the requirements engineer to identify both the problems and the solution strategies.

\subsubsection{Impacts of OT on Emotions, Values, and Beliefs}

OT and deployment of enabling CBSs, such as ERP systems, have a variety of impacts on the organization's employees. These impacts are often ignored in the specification of the requirements for the CBSs [66, pp. 306 and 235][69, pp. 46-47][71, pp. 41-44]. These impacts include:

- the CBS's degradation of the employees' quality of work life, by reducing job security and by increasing stress and uncertainty in pursuing task and career interests [71, pp. 55-70][17];

- the CBS's impact on the informal communication responsible for friendship, trust, feeling of belonging, and self respect [11, p. 145][17][38][85];

- the power imbalances the CBS will cause [3,64]; and

- the employees' loss of work and life meaning, which can lead to depression [71, pp. 41-49][46].

Recent work by Marina Krumbholz, Neil Maiden, et al investigates the impact on user acceptance of ERP induced OT that results from a mismatch between the ERP system's actual and perceived functionalities and the users' requirements, including those motivated by their values and beliefs $[55,56]$. This investigation was necessarily done after the fact. The authors agree with Krumbholz, Maiden, et al that it is more effective in the long run to attempt to find these impacts during RE rather than after implementation simply because it is about two orders of magnitude cheaper to find and fix faults during RE than after implementation [5].

\subsection{Examples of Requirements Affected by Emotions, Values, or Beliefs}

Ramos, in carrying out case studies for her Ph.D. dissertation [76,79], examined four organizations around Portugal, in businesses and universities, that were attempting CBS-enabled OTs. She found many examples of software features that raised fears in some stakeholders and of some CBS development processes that were affected by emotion-driven agendas of some stakeholders. We examine four of these examples, one from each case study, here.

(1) A software system that was supposed to store information about mistakes and who was responsible for them stressed out many potential users to the extent that the mistake-logging features had finally to be removed. 
(2) A university library was installing a centralized software system. It was planned that all staff members would have access to all stored information so that it would be easier for all to participate in decision making, and all would have more opportunities for autonomy and creativity. These effects were worthy goals. However, this increased access stressed out some potential users, who really preferred not to have access to information not specifically related to their own tasks. They were not interested in having more responsibility and more autonomy and in being more creative. They were comfortable with their current low-responsibility jobs that allowed them to get paid regularly for doing jobs that required very little thinking and no initiative, and they resisted the new work practices. Much of the work in libraries follows international standards and norms that create a culture of dependency on management decision and control and that inhibit creativity.

In this case, Ramos found that many voiced the idea that complying to standards and norms implies the inhibition of creativity. There does not appear to be any experimental evidence that in fact complying to standards and norms does indeed inhibit creativity. However, this notion is apparently believed by many and is actively used as a reason for opposing the imposition of standards and norms ${ }^{2}[89,19]$. Perhaps the thinking is, "If we have to follow international standards, and best practices, why should creativity be valued?"

(3) One company had installed an off-the-shelf (OTS) ERP system that met the company's requirements. The company was trying to motivate people to use it to its full potential. The charismatic leader of the resource planning department viewed the system as reducing the influence of his department and as inhibiting his own promotion as director; he began to actively, but surreptitiously, sabotage ${ }^{3}$ the use of the new system. This leader's sabotage efforts were so successful that the installation was shelved. This leader just convinced the company that the OTS product was bad and then began an in-house development of a CBS of nearly identical functionality. The advantage of the in-house system over the OTS system was that the slow development would give the leader and

$\overline{2}$ Even we software engineers commonly use this assumed implication as an argument against imposing or following a standards-complying software development process!

3 How did Ramos know that the leader was engaging in sabotage if it was surreptitious? The researcher was following an accepted qualitative method, participant observation. She observed the leader's behavior, reports that he was submitting, and things he was saying, and formed a locally constructed assumption (similar to a hypothesis) that he was actively sabotaging the introduction of the new ERP system. Then, she validated the assumption by asking questions of various people and observed that their answers were consistent with the assumption. Thus, she was able to conclude that the leader's behavior constituted sabotage. 
his staff a chance to learn and to teach the system more gradually, and thus become indispensable to the company. In other words, the OTS system was not implemented here, i.e., "NIH"! The in-house development made the charismatic leader so strong that he was able to defeat the intentions of the company's administration. It was ironic at the end, that after the leader won his war and got his promotion as the director of the department, he proposed the installation of a new ERP system to better control his own staff's work and performance.

(4) In an university, a computer supported cooperative work (CSCW) [24] system was introduced to the classroom to allow the students of a team to work together and the faculty member to observe the students' progress. This CSCW system stressed out students

- who had never worked before in teams,

- who did not work well in teams,

- who did not trust others not to mess up their own work, which had been made accessible to others,

- who did not like the idea of instructors observing their work closely in real time, or

- who freaked out when they found files they were editing being modified, as they were working, by others.

The students were used to asking and being asked for changes in the text as a result of discussions in or outside the classroom. Such changes, while frequent, appeared at least deliberate. Now, however, the whole process seemed beyond control.

In each of these and other cases, the proposed or current CBS caused fears among users because the CBS stood against their emotions, values, and beliefs. The introduction of the CBS was a failure or was not as successful as had been hoped. It would have been useful to have had a way to detect these problems before the implementations of the CBS had even started, during $\mathrm{RE}$, or at least, before the implementation had progressed very far. Detecting these problems early enough would allow properly addressing them either as changes to the CBS's requirements or by better employee and user training and relations.

The literature is replete with other examples of the emotional aspects of RE [e.g., $[55,56,3,35,46,83,8]$.

\subsection{Are These Just Managerial Issues?}

Some who have read earlier drafts of this paper accept that there indeed may be the kind of problems mentioned when deploying job-changing CBSs. However, they regard them as managerial problems and not as requirements 
problems. In one sense, these readers are right, in that the responses to these problems require action by management, addressing social issues.

However, any problem that can prevent the successful deployment of a system, whether it be

- incorrect function,

- failure to notice tacit assumptions,

- or anything else

should be identified as early as possible so that dealing with it can permeate the entire system design and development process. Perhaps, a so-called managerial problem born of emotion can be solved by a simple change in functionality or user interface, e.g., by eliminating a hated feature entirely. Perhaps, managers and colleagues of the employees that hate the feature should clarify both the business strategy supported by the feature and the benefits of the feature to these employees. Delaying consideration of any problem drives up the cost of solving the problem once it is identified $[5,81]$. When viewed this way, all such problems become requirement problems, some of which may be solved by the software of the CBS. In the end, it may very well be that the decided-upon solution to an identified problem may be considered a managerial solution, e.g., educating users and their managers, providing incentives for adopting, etc. However, such solutions, especially that of educating users, may be applied also to what might appear to be a functional or user-interface issue [60].

\subsection{Summary}

This section has discussed OT supported by the deployment of enabling CBSs. Specifically, it has defined OT and identified typical goals for initiating OT. It has described as a myth the rhetoric one hears about how OT is to be done and has described what really happens. It has discussed organizations as separate and collective entities. It has defined emotions, values, and beliefs and has shown how they can be impacted by OT. It has exhibited several examples of requirements impacted by emotions, values, or beliefs. The section has concluded with a discussion of whether these emotional impacts are just managerial problems. The requirements engineer who is elicting requirements for enabling CBSs for an OT must be aware of all these issues as he or she seeks out the emotions, values, and beliefs impacted by the OT and its enabling CBSs. 


\section{RE for OTs and their CBSs}

The modern requirements engineer has a new mission above and beyond that of finding functional and nonfunctional requirements of CBSs that enable an OT. He or she must find emotions, values, and beliefs affected by the CBSs and the enabled OT early enough so that they can be dealt with like any other factor affecting the requirements of the CBSs. For the remainder of this paper "emotions, values, and beliefs" is summarized by "emotional issues" except when we wish specifically to emphasize the values and beliefs. Therefore, we need to add to traditional RE methods, the ability to find the emotional issues. Note that other human work science disciplines, such as HCI [23] and CSCW [2], have similar needs to seek out emotional issues of the systems they build.

How do we identify emotional issues that can affect requirements for a CBS? It would be nice to have a systematic method that would guarantee finding all such issues. However, the history of failed CBSs $[32,33]$ is proof that there is no method that guarantees finding even all technical issues that can affect requirements for a CBS. Add to this uncertainty the less than stellar success rate of psychological and sociological treatments $[65,86,42]$, and it is clear that there can be no systematic method to find all emotional issues that can affect requirements for a CBS.

Thus, the best we can do is to teach requirements engineers to be aware of and to observe the way human beings reveal their emotions about the CBSs for which they are or will be users. We need to teach a requirements engineer to identify relevant emotional issues as he or she carries out his or her preferred methods to identify the usual kinds of functional and nonfunctional requirements. We need to teach a requirements engineer to consider alternative functionalities when it becomes clear that the emotional responses of users to a CBS suggests that deployment of the CBS will not achieve the purposes of the deploying organization. We need to teach a requirements engineer to warn the stakeholders about potential emotional reactions to desired features and to help the stakeholders in negotiations to find an appropriate mitigation to the reactions. Of course, all these new activities should be carried out in the framework of the traditional activities of the requirements engineer's job with the usual responsibilities and mandates.

The rest of this section on requirements elicitation describes how a requirements engineer can add the search for emotional issues to his or her usual methods. It provides lists of symptoms of emotional responses for which the requirements engineer should be on the look out. It may even be useful to consider adding to an RE team a person trained in psychology to identify and deal with emotional issues. 
Basically, the requirements elicitation approach being suggested in this paper is exactly the research approach that Ramos followed in her case studies. In other words, the requirements engineer has to treat each organizational problem situation as a case study in understanding the organization that is planning to do OT with the help of CBSs whose requirements are eventually to be specified. Even if the original project concept document mentions only software or a CBS and fails to consider OT, the problem must be considered that of OT with the CBS as the enabler so that the needs and emotions of the people and organization using the CBS are considered in the requirements elicitation.

In each case study, Ramos studied an organization that was having problems carrying out OT with an existing CBS, with a to-be-constructed CBS, or with a mixture of both. She went into the organization to get to know the organization, its people, its business, and its needs. She observed carefully how the people were behaving, with the old CBS if it was still being used, with the new CBS if it was already deployed, and in the discussions about the new CBS if it had not already been deployed or even implemented.

As Ramos was observing, she formed hypotheses about the people's emotions, values, and beliefs. For each hypothesis, she derived implications of the hypothesis and predicted the behavior of the people involved. If she later observed the predicted behavior, she accepted her hypothesis as an explanation of what she was observing. If not, then she revised her hypothesis and tried prediction and observation again.

Slowly, Ramos accumulated a sufficient number of confirmed hypotheses that she felt that she understood the organization, its people, and its OT problems. She prepared her report and delivered it to the organization's management. In two of the cases, this management specifically and explicitly requested Ramos's recommendation for a solution to the organization's problems that she had identified in her report.

In each of these two cases, Ramos then formulated solutions at the requirements level. Based on her understanding, she felt that these solutions would both address the organization's stated and observed problems and be accepted by the people of the organization. In other words, she felt that these solutions would meet the organization's requirements and that they would lead eventually to a successful OT. The proof, however, is only in the pudding. She regarded herself as successful only if her solutions in fact led to a successful OT, as evaluated by the client's satisfaction. In each of these two cases, the organization's management implemented her recommendations and were happy with the results.

This way of working can be recognized as a constructionist approach $[50,70]$ : 
Constructionism is the social theory that views human beings as active constructors of their knowledge; according to this theory, this knowledge construction happens more effectively when the individuals are involved in the construction of something external, something that can be shared, or both. Each of Ramos's roles, of researcher or of requirements engineer, involved her participation in deploying a CBS, a process leading to the social construction of knowledge about the CBS's support and use. Interestingly, all knowledge that was constructed in either role ended up being useful for the purposes of both roles. Thus, understanding the approach requires understanding constructionism.

An important concept that was used to guide Ramos's work is the four $d i$ mensions of work. The four dimensions of work in an organization concern organizational perspectives on individual and group action in the organization:

- The structural dimension of work is the formalized aspects of the organization, e.g., the organizational chart, the formal policies, and the official communication channels.

- The social dimension of work is the aspects that affect one's ability to participate in decision making.

- The political dimension of work is the aspects that affect one's ability to negotiate individual or group interests.

- The symbolic dimension of work is the aspects that affect one's ability to to deal with the ambiguity and uncertainty of decision making in the organization.

The approach we offer is not a method in the traditional sense of a step-by-step procedure or process to be followed by the requirements engineer. Rather, it is a collection of lists of questions to ask, behavioral clues for which to watch out, etc., i.e., guidelines that the requirements engineer can use to help her do her job. From where did these guidelines come? They were gathered from an initial review of the organizational theory literature, and then adapted to requirements elicitation by Ramos as she carried out her case studies. Thus, coming to play in the elicitation approach is organizational theory $[11,66,69]$. In fact, the initial case studies found more new questions and behavioral clues than did later ones, simply because in later case studies, she was able to reuse questions and behavioral clues from previous studies. These guidelines represent all that she found useful in all of her case studies. The authors plan to use them in any requirements elicitation that they do in the future.

That this approach works and that these guidelines are useful is supported by Ramos's successful requirements elicitation efforts in two of the case studies. The results of the efforts are discussed in Subsection 3.6. 
The remainder of this section

(1) discusses traditional RE, with its assumption of an objective reality, and its shortcomings in working with OTs,

(2) discusses constructionist RE, with its assumption of a socially constructed reality, as a more suitable framework for RE for CBSs for emotion-laden OT,

(3) gives organizational-theory-derived guidelines, i.e., lists of questions and behavioral clues for which to watch out,

(4) pulls it all together in a constructionist requirements elicitation process,

(5) describes two case studies of constructionist RE, and

(6) discusses weaknesses of the guidelines.

\subsection{Traditional RE}

Traditionally, RE assumes an objective reality [21,20,84,62,87,4,52,77,90,67]. An objective reality is a reality that is assumed to exist independently of any observer. For this reason, it is reasonable to expect that an objective reality's details can be systematically elicited and straightforwardly expressed in writing by people who engage in honest, systematic observation guided by well-tested methods of observation. Moreover, for an objective reality, it is reasonable to also expect that any person using such observation methods will elicit and express the same details. Thus, if reality is objective, the effort in requirements elicitation is in eliminating observer bias. If two observations differ, logic dictates that at least one of them must be wrong. In other words, multiple perspectives are neither to be sought nor to be tolerated. If there were to be an objective reality, the requirements engineers would simply elicit information from the reality and proceed systematically to a requirements specification.

However, all the emotional problems mentioned in Subsection 2.4 say that at least part of the reality with which CBSs for OT must deal cannot be objective, but must be socially constructed by the people involved in, affecting, and affected by the OT. Indeed Lehman [57] observed that, once deployed, software embedded in the real world - and surely software for OT is embedded in the organization attempting OT - becomes inextricably part of its environment and ends up changing its own requirements. Goguen has observed that "It is not quite accurate to say that requirements are in the minds of clients; it would be more accurate to say that they are in the social system of the client organization. They have to be invented, not captured or elicited, and that invention has to be a cooperative venture involving the client, the users, and the developers. The difficulties are mainly social, political, and cultural, 
and not technical." 4 , that is, not only is the reality in which software operates socially constructed, but so are the requirements for that software. Thus, we might then expect that the deployed software itself becomes part of that socially constructed reality.

\subsection{Constructionist RE}

According to the constructionist perspective [50,70], knowledge is a social product, actively constructed through direct interaction with the environment. In this sense, knowledge is a real-life experience. As such, it is personal, sharable through interaction, and its nature is both rational and emotional. Knowledge representation is intimately connected with the knower-as-teacher and the learner. Knowledge representation is never complete or accurate since it can never replace the experience from which it is derived. When we add the normal requirements creep that happens as a result of system deployment [57], it is clear that requirements change is relentless. Hence, no matter how well we have elicited and invented requirements, there will always be heretofore undiscovered and unconveyed requirements. A system requirement is a specific form of knowledge representation. However, a knowledge representation can be useful if it makes ideas tangible and enables communication and negotiation of meanings.

The assumption that reality is socially constructed has implications for practice of $\mathrm{RE}[82,1]$. The requirements engineer must understand the implications of socially constructed knowledge. The requirements engineer must be aware of how and when particular kinds of knowledge are created during RE in order to know when to be observing and for what to be looking during the observation. These hows and whens are summarized in Table 1. This table works on three subprocesses of requirements elicitation:

(1) the creation of knowledge about the current work situation, perceived problems or expectations, and the vision of a new work situation that includes the use of a CBS that supports or implements innovative work concepts and practices;

(2) the representation of the created knowledge; and

(3) the joint invention by all stakeholders of requirements for a CBS that acceptably meets all stakeholder's needs, expectations, or interests.

These subprocesses, of course, are interconnected processes that are described

$\overline{4}$ This quotation is from a draft that preceded publication as a chapter in a book [36]. The quotation did not survive into the book chapter. However, by e-mailed

personal communication, Joseph Goguen assures us that he still believes in the contents of the quotation and that he does not disown it. 
Table 1

How and when particular kinds of knowledge are created during a constructionist RE process

\begin{tabular}{|c|c|c|c|}
\hline & Knowledge Creation & $\begin{array}{l}\text { Knowledge } \\
\text { Representation }\end{array}$ & $\begin{array}{l}\text { Requirements } \\
\text { Invention }\end{array}$ \\
\hline $\begin{array}{l}\text { Goals of RE } \\
\text { process }\end{array}$ & $\begin{array}{l}\text { Understand (1) human } \\
\text { action and interaction that } \\
\text { will be supported by the } \\
\text { software system and }(2) \\
\text { the meanings behind that } \\
\text { action. Question and } \\
\text { re-create those meanings. }\end{array}$ & $\begin{array}{l}\text { Express a multivoiced } \\
\text { account of the reality that } \\
\text { we construct socially. It } \\
\text { includes the voice of the } \\
\text { elicitor and all } \\
\text { stakeholders of the system. }\end{array}$ & $\begin{array}{l}\text { Reinvent the work reality } \\
\text { through the adoption of a } \\
\text { software system. }\end{array}$ \\
\hline $\begin{array}{l}\text { Structure of RE } \\
\text { process }\end{array}$ & \multicolumn{3}{|c|}{$\begin{array}{l}\text { The RE process structure is the result of the joint effort of system's } \\
\text { stakeholders and elicitors for emancipation, fairness, and community } \\
\text { empowerment. Its shape is situational, i.e., it varies with organizational } \\
\text { history and culture, and resources involved. }\end{array}$} \\
\hline $\begin{array}{l}\text { Final product } \\
\text { (i.e. } \\
\text { requirements) of } \\
\text { RE process }\end{array}$ & $\begin{array}{l}\text { Reformulation of mental } \\
\text { constructions, recreation of } \\
\text { shared meanings, } \\
\text { awareness of contradictions } \\
\text { and paradoxes of concepts } \\
\text { and practices. } \\
\text { Development of a common } \\
\text { and local language to } \\
\text { express emotions, } \\
\text { perceptions and } \\
\text { conceptions. }\end{array}$ & $\begin{array}{l}\text { Expression of individual } \\
\text { and shared experience. }\end{array}$ & $\begin{array}{l}\text { Shared interpretations of } \\
\text { adequate support of work. } \\
\text { Cannot be disconnected } \\
\text { from historical and social } \\
\text { contexts of requirements } \\
\text { creators. }\end{array}$ \\
\hline $\begin{array}{l}\text { Theoretical } \\
\text { frameworks of } \\
\text { RE process }\end{array}$ & \multicolumn{3}{|c|}{$\begin{array}{l}\text { Inform the RE process with the values and beliefs held by elicitors and } \\
\text { the system's stakeholders. }\end{array}$} \\
\hline \multirow[t]{2}{*}{$\begin{array}{l}\text { Methods, } \\
\text { techniques, and } \\
\text { tools of RE } \\
\text { process }\end{array}$} & $\begin{array}{l}\text { Inform the RE process } \\
\text { with the values held by } \\
\text { elicitors and the system's } \\
\text { stakeholders. Help create } \\
\text { graphical and textual } \\
\text { elements of a common } \\
\text { language. }\end{array}$ & $\begin{array}{l}\text { Define the organization of } \\
\text { knowledge representations. }\end{array}$ & $\begin{array}{l}\text { Define the format in which } \\
\text { requirements are expressed. }\end{array}$ \\
\hline & \multicolumn{3}{|c|}{$\begin{array}{l}\text { Have the potential of bias towards some stakeholders' voices and of } \\
\text { forcing a foreign language. }\end{array}$} \\
\hline $\begin{array}{l}\text { Role of } \\
\text { participants of } \\
\text { RE process }\end{array}$ & $\begin{array}{l}\text { Co-creators of knowledge, } \\
\text { jointly nominate the } \\
\text { questions of interest. }\end{array}$ & $\begin{array}{l}\text { Co-creators of a language } \\
\text { to represent knowledge, } \\
\text { jointly design outlets for } \\
\text { knowledge to be shared } \\
\text { more widely within and } \\
\text { outside the site. }\end{array}$ & $\begin{array}{l}\text { Co-inventors of a common } \\
\text { future. }\end{array}$ \\
\hline $\begin{array}{l}\text { Reuse of product } \\
\text { (i.e. } \\
\text { requirements) of } \\
\text { RE process }\end{array}$ & $\begin{array}{l}\text { Created knowledge is local, } \\
\text { transferable only for sites } \\
\text { where people have similar } \\
\text { experiences and beliefs. }\end{array}$ & $\begin{array}{l}\text { Representations are } \\
\text { connected with the context } \\
\text { in which they were created. } \\
\text { If transposed to a different } \\
\text { location, they may invoke } \\
\text { different mental } \\
\text { constructions in readers. }\end{array}$ & $\begin{array}{l}\text { Reuse of stakeholders' re- } \\
\text { quirements is problematic } \\
\text { because of their historical } \\
\text { and sociocultural dimen- } \\
\text { sion. }\end{array}$ \\
\hline
\end{tabular}


here independently only to simplify their analyses. The table has one column for each of these subprocesses. Each row represents the constructionist perspective about one aspect of the overall RE process: about

- the goals of the RE process;

- the structure of the RE process;

- the final product, i.e., the requirements, of the RE process;

- the theoretical frameworks of the RE process;

- the methods, techniques, and tools of the RE process;

- the role of the participants of the RE process; and

- the reuse of the product, i.e., the requirements, of the RE process.

The table element for each aspect and each process step describes how the aspect participates in knowledge creation during the process step. For example, consider the table element at the "Role of participants of RE process" row and the "Requirements Invention" column. Its contents, "Co-inventors of a common future", implies that the role of participants during requirements invention is to be co-inventors of a common future.

\subsection{Organizational-Theory Based Requirements Elicitation}

Recently, a number of authors, e.g., Bolman and Deal [11], Morgan [66], and Palmer and Hardy [69], developed integrated accounts of the organizational theory that had previously been developed by many other researchers. Ramos investigated the usefulness of bringing this integrated organizational theory into the requirements elicitation process [76]. She described the importance of the structural, social, political, and symbolic dimensions of work [11] in determining requirements. One result of this work are guidelines for understanding the meaning of human action and interaction that can be used during the observational phases of requirements elicitation. These guidelines are summarized in Tables 2 and 3.

Table 2 helps the requirements engineer to decide which stakeholders should be consulted during elicitation of requirements for a CBS. For each dimension of work, the table lists the properties of the individuals that must be chosen in order to have adequate representation of the viewpoint of that dimension. For example, to learn about symbolisms in the work affected by the CBS, among the representatives, the requirement engineer must consult

- at least one person who knows the jargon of the work,

- at least one person who knows the proverbs, slogans, and metaphors of the work, and

- at least one person who knows how to conceive the work's space. 
Table 2

Work aspects that should guide the choice of participants

\begin{tabular}{|c|c|}
\hline Structural & $\begin{array}{l}\text { Participants should be representative of: } \\
\text { Formal roles } \\
\text { Tasks } \\
\text { Skills } \\
\text { Levels of authority } \\
\text { Accessed/produced information }\end{array}$ \\
\hline Social & $\begin{array}{l}\text { Participants should be representative of: } \\
\text { Communication skills } \\
\text { Negotiation skills } \\
\text { Informal roles } \\
\text { Degrees of motivation to change work practices } \\
\text { Participation in the shaping of organizational history } \\
\text { Willingness and experience in decision making processes } \\
\text { Professional status } \\
\text { Knowledge }\end{array}$ \\
\hline Political & $\begin{array}{l}\text { Participants should be representative of: } \\
\text { Group interests } \\
\text { Form of power held: organizational authority, control of scarce } \\
\text { resources, control of the definition of formal arrangements, } \\
\text { restricted access to key information, control of organizational } \\
\text { borders, control of core activities, member of a strong } \\
\text { coalition, charisma }\end{array}$ \\
\hline Symbolic & $\begin{array}{l}\text { Participants should be representative of: } \\
\text { Use of jargon } \\
\text { Use of proverbs, slogans, and metaphors } \\
\text { Relevant beliefs and superstitions } \\
\text { Use of humor } \\
\text { Story telling } \\
\text { Responsibilities for symbolic events } \\
\text { Ways of instigating social routines and taken for granted } \\
\text { techniques to perform a task } \\
\text { Ways of conceiving the work space }\end{array}$ \\
\hline
\end{tabular}


Table 3

Dimensions of human action in organizations

\begin{tabular}{|c|c|}
\hline Structural & $\begin{array}{l}\text { Relevant organizational goals, objectives, and strategies } \\
\text { Tasks, processes, rules, regulations, and procedures } \\
\text { Communication channels and exchanged information } \\
\text { Coordination and control } \\
\text { Formal roles } \\
\text { How authority is distributed } \\
\text { Needs of system support to work } \\
\text { Relevant organizational and technological knowledge to be able } \\
\text { to perform tasks }\end{array}$ \\
\hline Social & $\begin{array}{l}\text { Shared goals and objectives } \\
\text { Performance expectations } \\
\text { Rewards or punishments for performance } \\
\text { Motivation factors } \\
\text { Informal roles and communication } \\
\text { Personal knowledge and its impact on work concepts, practices, } \\
\text { and relationships } \\
\text { Fostered participation in decision making } \\
\text { Use of individual and group skills }\end{array}$ \\
\hline Political & $\begin{array}{l}\text { Personal interests relating performed tasks, career progression, } \\
\text { and private life } \\
\text { Coalitions } \\
\text { Individual or group power plays } \\
\text { Conflict of interests } \\
\text { Negotiation processes: concepts, and practices }\end{array}$ \\
\hline Symbolic & $\begin{array}{l}\text { Symbols used to deal with ambiguity and uncertainty } \\
\text { Shared values and beliefs } \\
\text { Common language } \\
\text { Relevant myths, stories, and metaphors } \\
\text { Rituals and ceremonies } \\
\text { Messages relevant to organizational, work, or system stakeholders } \\
\text { Legitimized ways of expressing emotions }\end{array}$ \\
\hline
\end{tabular}


Of course, to keep costs down, it helps if one person provides several items of knowledge. However, too few people reduces diversity and limits the effectiveness of brainstorming and other knowledge-creation processes.

Table 3 shows for each dimension of work, the human actions and interactions that can be relevant to requirements. The table thus recommends bits of knowledge that should be sought during requirements elicitation for a CBS. For example, to make sure that the symbolic dimension of the work affected by the CBS is understood, the requirements engineer should seek to learn the symbols used to deal with ambiguity and uncertainty, to learn the values and beliefs shared by the stakeholders of the CBS, etc.

Observe that on a row-by-row basis, the stakeholders selected according to Table 2 are selected for their ability to provide the knowledge required by Table 3. However, the requirement engineer should not restrict asking questions about a dimension to that dimension's representing stakeholder. The diversity offered by the other stakeholders is essential.

Finally, note that we are not claiming that the knowledge sought by these tables is the only knowledge to be sought. On the contrary, all the usual knowledge about functional and nonfunctional requirements must be sought, and traditional methods that work for eliciting this knowledge should continue to be used, but integrated, as described in the next subsection, with the approach presented in this paper. Our point is that without the information sought in these tables, the information that is obtained by the requirements engineers is more likely to be deficient on the four dimensions of work and the CBS is more likely to be built with inadequate consideration of the emotions, values, and beliefs of the stakeholders.

\subsection{Towards a Constructionist Requirements Elicitation Process}

An organization wishing to engage in a constructionist RE process should embed it into whatever RE process it normally follows to elicit functional and nonfunctional requirements. The key is what to do with the knowledge that is already being gathered during this requirements elicitation. Recall that the constructionist approach regards all knowledge obtained during requirements elicitation to be created by the social process of elicitation. Therefore, during requirements elicitation, all created knowledge should be continually consulted in order to learn not only functional and nonfunctional requirements, but also how previous and current historical, social, and cognitive experiences have been shaping the process of knowledge creation. The process is no more than the usual continual validation with stakeholders of what the requirements engineer learns [77]. 
Tables 2 and 3 should be followed to create the knowledge about emotions, values, and beliefs that is relevant to the deployment of the CBS whose requirements are being gathered. While creating the knowledge elements described in these tables, elicitors and the system's stakeholders participate in conversations. During these conversations, this knowledge is being constructed and internalized by all participants. This interplay creates a common reality for the elicitors and the stakeholders.

During requirements elicitation (and actually at any time), emotions and unconscious experience and knowledge can be observed only indirectly through the participants' actions and reactions and through their use of language in its most general sense [49]. Some behavioral symptoms of emotions are:

- vocal characterizers (noises one talks through, e.g., laughing, whispering, yelling, crying);

- vocal segregates (sounds used to signal agreement, confusion, understanding, e.g., "Hmm-hmm", "Huh?!", "Ah!", "Nu?!");

- voice qualities (modifications of language and vocalizations, e.g., pitch, articulation, rhythm, resonance, tempo);

- idiom (dialect, colloquialism, jargon, slang);

- discourse markers ("well", "but", "so", "okay");

- stylistic devices (use of repetition, formulatic expressions, parallelism, figurative language, onomatopoeia, pauses, silences, mimicry);

- facial expressions (smile, frown, furrowed brow);

- gestures (nodding, arm and hand movements);

- shifts in posture;

- alterations in positioning from or to intimacy (touching) to or from social or public distance;

- performance spaces (an allocated room or impromptu meeting in a corridor, rearranged seating, etc.);

- props (especially for ceremonial oratory); and

- clothing, cosmetics, and even fragrance.

Of course, the meanings of these symptoms have to be deduced. Here, psychological expertise and experience is essential, and as mentioned, it may be worth having a psychologist on the RE team.

These guidelines for finding the emotional issues are only guidelines, and they help find only the emotional issues. They do not constitute a complete RE process. These guidelines must be applied as a part of a complete RE process that leads from requirements elicitation through requirements analysis and specification to validation of the specification with the stakeholders. These processes, including the following analysis processes

(1) ranking requirements by costs, benefits, preferences, etc. by the individual 
stakeholders,

(2) negotiation among stakeholders for a common ranking of requirements,

(3) requirements scoping,

(4) tracing among requirements,

(5) tracing between requirements and other artifacts,

are to be performed as usual, except with some additional kinds of requirements, i.e., emotional, sitting in the bag.

\subsection{Comparison with Other Work}

The basic assumptions of the constructionist perspective, from which Table 1 is derived, are already implicitly integrated into the Soft Systems Methodology (SSM) [14]. Authors in RE have been emphasising the interconnectedness of science, society, and technology [37] and the relevance of ethnographic techniques for eliciting requirements in their context $[62,38]$.

Karen Holtzblatt [44], Joseph Goguen, and Marina Jirotka [34] have been saying for years that each requirements engineer must be a bit of a sociologist, to explore the social system in which a proposed CBS will be embedded. They have been arguing in essence that there is no simple, systematic requirements elicitation method of the kind that many hope would exist. These systematic methods depend on there being an objective reality. Instead reality is socially constructed, and the requirements engineer must get socially and personally involved in that reality in order to learn what is needed for requirements elicitation and in order to help the organization invent the requirements for a socially constructed solution to their problems.

Marina Krumbholz et al have studied implementation and deployments of variations of the same ERP system in multiple locations of a single binational company that made its living selling the products it manufactured $[55,56]$. Implementing and deploying a variant of this system means choosing parameters and generating an instance of the standard package that is then ready for immediate use. The company hoped that the ERP system would improve the operations of the whole company, and started by implementing variants of the system for two departments, (1) sales and distributions and (2) warehouse management, each of which had a location in each country. They noted user acceptance problems, i.e., complaints, avoidance, by passing, etc., as a result of a mismatch between user requirements and the perceived and actual functionality of the implemented ERP. Users complained, sometimes quite vociferously, of a poor fit to their needs; of poor quality software; of inappropriate, clumsy, and slow user interface; that the software was too rigid to adapt to their needs; and things were better with the old bespoke system. 
The purpose of their study was to measure the impact of culture, both organizational and national, on the implementation and acceptance of ERP packages. They noted that a poor match between a package's perceived or actual functionality and user requirements caused negative emotions about an ERP system. These problems could be fixed after their discovery in several ways, including changing the implementation and educating the users about package capabilities. The proposal of the present paper is to try to determine the potential acceptance problems during RE time, before the system is implemented, by paying attention to emotions, values, and beliefs during requirements elicitation. The hope is that a better fit between function and requirements, including those about emotions, values, and beliefs, can be achieved from the start.

However, few specific guidelines have been provided to deal with the impact of emotions, beliefs, and values of the whole team involved in a requirements elicitation. There is also a shortage of guidelines to help elicit emotions, beliefs, and values from the visible and shared constructions of human action and interaction that occur in organizations.

\subsection{Confirmation of the Effectiveness of Constructionist RE}

As mentioned earlier in Section 3, Ramos did four case studies in organizations around Portugal for the purposes of learning how to do constructionist requirements elicitation. These studies led to the refinement of the guidelines presented in Subsections 3.3 and 3.4, including the tables and the list of behaviors to seek. In each of two of these organizations, after she had filed her report describing what she had learned, the report recipients asked her to make recommendations to help their organization carry out the problematic OT in which they were involved. She agreed, and made requirements-level recommendations, which were subsequently followed with positive results.

Thus, two of the constructionist requirements elicitation case studies evolved into constructionist RE case studies making use of the same knowledge constructed during the earlier requirements elicitation studies using the tables and the list.

This section details these constructionist RE case studies in order to show how the constructed knowledge led to requirements recommendations. While these case studies cannot amount to a true validation of the approach, they do confirm that the approach worked twice in real-life situations and they suggest that more work is needed to validate the approach in the future.

Case 1 is the second mentioned in Subsection 2.4, and Case 2 is the third mentioned in Subsection 2.4. The descriptions given in Subsection 2.4 are 
assumed in the following discussions.

(1) The study took place in the library of a university in Portugal. The new system that was being adopted was going to support integrated management of the library. This system was not fully implemented at the time of the study. The system consists of several interconnected modules supporting specific librarian activities. It was both an open and a clientserver system, and the implemented modules were running under a UNIX operating system. When fully implemented, the system would support

- acquisition of the library's resources,

- control of periodicals,

- cataloguing of the resources,

- search for bibliographic records,

- diffusion of information,

- loan management,

- control of existing resources,

- production of statistical reports, and

- automatic connection with email servers.

The research performed in the library was a case study and not action research. So, Ramos was there to observe, to interview, and to elicit meanings and practices. Nevertheless, the research report was used by the library's manager to guide him in decisions related to the implementation of the full system.

The report surprised him by showing him that his employees valued his close supervision and control. Consequently, he ended up asking for implementation of more functionalities and reports that would support him in this supervision and control. He had been postponing his decision about the amount of control he would be exercising, vacillating between tight and loose control, and leaning towards the latter because it was considered good to give employees more autonomy. However, Ramos's report clearly showed him that close control would be welcomed by his employees.

The report indicated also that the organizational culture of the Librarystrict adherence to rules and procedures - was in conflict with the need of students to flexibly and rapidly access the library's resources without the constraints and delays imposed by what they perceived as bureaucratic rules and procedures. The director decided to invest in e-services for the students that would allow the students flexible access to information services and resources, while keeping the stability of the current work environment for the employees.

The report helped the library director also to focus the training programs for the employees on the specifics of the use of the software, thus helping most people specialize in their own task.

Ramos used the guidelines presented in Sections 3.3 and 3.4 to help her get the information for writing her report. Even though she had not 
initially planned to do any requirements specification, in fact, her report identified many requirements. Most importantly, the recipients of the report acted upon them to change the course of the OT from heading to a failure to being a definite success.

(2) The study took place in a Brazilian-funded-and-owned company in Portugal whose clients include the most important automobile manufacturers in Europe. By 1998, the company was sold to a German group. The studied work realities were substantially more complex than in the library. They included a larger number, twenty, of actors from several subcultures with different and sometimes divergent interests. The study was performed in the two most influential departments of the company, the Finance Department and the Logistics Department. The studied system supported the planning and management of plant production. It had been used during the previous six years, haven been implemented at the beginning of the operation of the plant. In the Finance Department, Ramos studied the use of the modules of the system needed to perform the accounting tasks. In the Logistics Department, she studied the use of the modules that supported the purchase of items for the plant, the purchase of raw material, the processing of customer orders, and the management of production orders. Surprisingly, the production planning functionality of the system was never used. The production planning was performed outside the main system.

The research method for the company was also only a case study. The main aim of the research was to understand the reasons that there were so many difficulties in getting the employees to accept the new system. Ramos was as careful as possible to avoid influencing events in the company.

Ramos observed a tension between a charismatic man, hereinafter known as Francisco (not his real name), from the Logistics department, and the Management Information Systems (MIS) department. The Logistics department faced continually changing orders from clients and difficulties with not always reliable suppliers. To the people in the Logistics department, the current ERP system was incapable of dealing with their unstable enviroment. Consequently, Francisco requested from the MIS department adding numerous new functionalities to the ERP. The MIS director refused these requests for valid reasons: he knew that most functionality of the ERP was not being explored and effectively used; that most of the requested functionality was already in the non-used functionality of the ERP; and that providing the exact requested functionality as an addition would make updating the resulting ERP very difficult and expensive.

In reaction to these refusals, Francisco began to develop the requested functionality in a parallel system, built on Excel plus VisualBasic. The MIS director responded by explaining the reasons for his refusals and asked that Francisco be patient and wait until the MIS group could pro- 
vide the requested functionality out of the existing ERP system. Nevertheless, Francisco continued with the development of the parallel system without reporting either what the parallel system was doing or the changes it introduced to the data in the central database. At a certain point, Francisco started complaining about the poor quality of the information in the central database, despite the fact that he was one of the main agents of this poor quality by virtue of his use of a parallel system instead of the officially sanctioned ERP system!

Francisco's complaints were heard and acted upon by the administration. In an interview, Ramos noticed that Francisco was trying to assume responsibility for the Logistics department. He kept saying, "We did ..." and "We thought ...", and then correcting himself by saying, "I did ..." and "I thought ...". Several days after this interview, the official Logistics department director was fired and Francisco got the director's job. Also the MIS director left the company under pressure from the administration of the company. These activities by Francisco constitute the sabotage described in Section 2.4.

The issue with the sabotage is not that it was not justified. The existing ERP system was too complex to allow people to explore it to discover its complete functionality and thus to be able to do what they needed to do in the existing system. As the existing system was configured, it was too rigid to allow the Logistics department to deal with the varying requests of clients and the unexpected problems with the suppliers. This rigidity was creating even more difficulties in the relationships between the company and its clients and suppliers. These problems impacted the Logistics department, which was not being involved in the decisions about the tradeoffs of replacing the system or re-programming functionalities. Thus, to some extent, Francisco's actions to get the needed functionality were justified.

Ramos's research connected the unstable environment of the Logistics department with the complexity and rigidity of the existing ERP system, showing that the existing system was not the best for the Logistics department, no matter the marketing hype usually associated with ERP systems.

This connection had not even been acknowledged by the MIS director, primarily because of his emotional attachment to the existing ERP system. He had been hired specifically to design the ERP processes and to procure and manage a supporting information systems when the company started, some six years before the study.

Had the connection been understood before, Francisco in the Logistics department would had been involved in decisions relating to the design of the ERP processes and system. His involvement could have avoided the sabotaging behavior. However, the MIS director kept fighting Francisco's requests, perhaps because he saw them, albeit correctly, as aiding Francisco's ambition for Logistics to become more autonomous and to 
operate independently of the MIS department.

The complexity of the system should have been recognized and specific procedures to support the exploration of the system should have been implemented, despite the delays these procedures could cause to daily work. If these delays would end up not being tolerable, then people should accept what was happening: the system was not understandable enough to be used to its full potential. As it was, people were both pressed to respond quickly to daily problems and blamed for not being able to learn more about the ERP system's functionality!

For more details, please consult Ramos's Ph.D. dissertation [76], a paper derived from it [79], or the REFSQ'02 paper published by Ramos and Carvalho [80].

In the case studies, had not the information in Ramos's reports been available and acted upon, then it is likely ${ }^{5}$ that the outcomes could have been radically different.

(1) In the library, the librarian could have gone ahead and implemented the looser control to which he was leaning. He could have committed OT resources to developing features in the library system that would allow the employees the flexibility to be as creative as he was hoping that they could be. The employees could have rebelled against the new freedoms, refusing to exercise them in order to avoid assuming responsibilities and to avoid being blamed in the event that a mistake were made. The students, who did want the flexibility to be creative, could have remained dissatisfied with the library's system, because after wasting resources on unused functions for the employee and wasting still more fighting with the employees, the library could not have the resources to implement the functions that the students wanted.

(2) In the company, the management could have stood behind the MIS manager, insisting that the current ERP system be fully utilized and be used to provide all functions it could support. The employees who could not understand the current system could have rebelled, refusing to do more than they were already doing. Some of these employees could have resigned from the company. Francisco could have left the company. Without its charismatic leader, Francisco, to galvanize action, the Logistics Department's interaction with customers and suppliers could have deteriorated, eventually alienating both from dealing with the company.

5 Strictly speaking we can say nothing of the sort. It is impossible to rewind life and run it again as it would have under different choices. The best we can do is guess at a plausible outcome based on other experiences we have had in the past. The particular scenarios given here represent plausible worst-case scenarios. To remind the reader that these are only possible scenarios, we use "could" instead of "would". 
The reader may very well say that the problems observed in the case study are quite common and are really signs of poor management practices and are not requirements or software engineering problems. To these readers, we offer the following remarks:

To the extent that the problems observed affected the choice of functions of the CBS being deployed and even the choice of CBS, these problems are requirements problems. As with any other requirements problem, the sooner they are identified, the cheaper they are to fix. Sometimes, the fix involves so-called managerial solutions, such as user education. Sometimes, the fix involves changes in the functionality of the CBS or even of the entire CBS being deployed. Even with traditional functional and nonfunctional requirements issues, the fix to a requirements problem may be a so-called managerial solution, e.g., leaving the CBS the way it is and training users to apply different functions and to avoid the problematic ones [60].

\subsection{Limitations of the Approach}

No method is guaranteed to work in every situation, least of all one that is dealing with human emotions. While the requirements engineer steps into a project with every intention of finding a set of requirements that satisfies the relevant needs of all stakeholders, in any given project, the requirements engineer may fail to find satisfactory requirements because the emotional needs of some stakeholders are too strongly opposed to each other. The requirements engineer may be forced to conclude that the proposed system cannot be built. Certainly a practitioner of WinWin [6] does not always find a sent of conditions that make all stakeholders winners. There may be in a given case, at least one losing party no matter how the requirements are formulated. However, we see this unfortunate situation as not different from the usual algorithmic, technical, and economic feasibility studies that should be part of all RE efforts. It is accepted that the conclusion of such a study is that the proposed CBS is infeasible, concluding, e.g., that the required algorithms are not computable, that the required technology has not been invented yet, or that the resources required are just not available. In such a case, the requirements engineer is forced to report that the proposed CBS should not be built. Thus, we accept total inability to satisfy stakeholders' emotional needs as another kind of infeasibility, which, along with algorithmic, technical, and economic infeasibility, can lead to project termination.

Another possible cause for failure of the method is that despite all efforts to elicit all relevant emotions in all stakeholders, the requirements engineer may fail to find one or more relevant emotional issue. Here again, this failure is not different from a failure to find a usual functional or nonfunctional algorith- 
mic, technical, or economic requirement, what Don Gause calls "nature's last laugh" [31].

\section{Conclusions and Future Work}

This paper was written with the aims of

(1) addressing the implications of emotions, values, beliefs beliefs in OT and in deployment of CBSs that enable OT, and

(2) advancing a constructionist RE process and some guidelines to eliciting the emotions, values, and beliefs relevant to requirements for these CBSs.

The constructionist approach to requirements elicitation embodied in the questions of the tables and the list of behaviors is lengthy and resource intensive. However, following the approach gets the requirements engineer totally involved in the construction of the work reality that is the goal of the OT.

Addressing only the functional, structural, and economic aspects of the process, as is the case in traditional RE, would mean to ignore that emotions are present even in our most rational and objective decisions [18]. In the elicitation of requirements, emotions are present in the choice of the problem to address, the choice of techniques and tools to gather information about business goals and work practices, the choice of stakeholders and the needs they express, the abstractions and partitions of reality, the knowledge we find relevant, the requirements we elicit, and the formats in which we choose to represent knowledge and requirements. Ignoring these emotions yields deficient requirements specifications.

This paper has presented case studies that were used to derive the approach from an organization-theory based approach and to confirm that the derived, constructionist approach works for real-life RE. The effectiveness of the approach was confirmed for two case studies. More case studies are needed to do a more substantial validation.

In the future, the authors plan to investigate post mortem reports for some failed IT system deployments, e.g., the deployment of the London Ambulance System [29,28] and the deployment of CAPSA, the Cambridge University's new on-line accounting system [30], to try to cast the failures as failures to deal with the stakeholders' emotions, values, and beliefs during their RE processes.

The authors intend also to develop an approach that will structure requirements elicitation around the four processes that mold socially created realitiessubjectification, externalization, objectification, and internalization - and that 
will make use of the above guidelines and of strategies to effectively influence the transformation of emotions, values, and beliefs. An initial version of this approach has already been developed and tested in the field, but it needs to be improved in future action research projects. The authors do not intend to invent new techniques or a new method to guide requirements elicitation. Rather, they intend to provide a general framework in which existing methods and techniques could be integrated or reconstructed.

\section{Acknowledgments}

The authors thank the anonymous referees of all previous versions of this paper for their helpful comments. They thank Danny Heller, Adie Nelson, and Jonathan Oakman for help tracking down some references.

\section{References}

[1] I. Arbnor and B. Bjerke, Methodology for Creating Business Knowledge, (Sage, Thousand Oaks, CA, 1997).

[2] R.M. Baecker, ed., Readings in Groupware and Computer-Supported Cooperative Work: Assisting Human-Human Collaboration, (Morgan Kaufman, San Francisco, CA, 1993).

[3] M.B. Bergman, J.L. King, and K. Lyytinen, Large-Scale Requirements Analysis Revisited: The need for Understanding the Political Ecology of Requirements Engineering, Requirements Engineering Journal 7:3 (2002) 152-171.

[4] D.M. Berry and B. Lawrence, Requirements Engineering, IEEE Software 15:2 (March 1998) 26-29.

[5] B.W. Boehm, Software Engineering Economics, (Prentice-Hall, Englewood Cliffs, NJ, 1981).

[6] B.W. Boehm, P. Bose, E. Horowitz, and M.J. Lee, Software Requirements As Negotiated Win Conditions, Proceedings of the First International Conference on Requirements Engineering (ICRE94), Colorado Springs, CO (1994) 74-83.

[7] B.W. Boehm, P. Bose, E. Horowitz, and M.J. Lee, Software Requirements Negotiation and Renegotiation Aids: A Theory-W Based Spiral Approach, Proceedings of the Seventeenth International Conference on Software Engineering (ICSE'95), Seattle, WA (1995) 243-253.

[8] B.W. Boehm and L.G. Huang, Value-Based Software Engineering: A Case Study, IEEE Computer 36:3 (March 2003) 33-41. 
[9] B.W. Boehm and R. Ross, Theory-W Software Project Management: Principles and Examples, IEEE Transactions on Software Engineering 15 (1989) 902-916.

[10] D.M. Boje, R. Gephardt, and T.J. Thatchenkery, Postmodern Management and Organization Theory, (Sage, Thousand Oaks, CA, 1997).

[11] L.G. Bolman and T.E. Deal, Reframing Organizations: Artistry, Choice, and Leadership, Second Edition, (Jossey-Bass, San Francisco, CA, 1997).

[12] F.P. Brooks, Jr., No Silver Bullet, Computer 20:4 (April 1987) 10-19.

[13] W.W. Burke, Organization Change: What We Know, What We Need to Know, Journal of Management Inquiry 4:2 (1995) 158-171.

[14] P. Checkland and J. Scholes, J., Soft Systems Methodology in Action, (John Wiley \& Sons Ltd., Chichester, UK, 1990).

[15] R.B. Cialdini, Influence: Science and Practice, (Harper Collins College, New York, NY, 1993).

[16] T.G. Cummings and C.G. Worley, Essentials of Organization Development and Change, (South-Western College Press, Mason, OH, 2000).

[17] B. Dahlbom and L. Mathiassen, Computers in Context: The Philosophy and Practice of Systems Design, (Blackwell, Oxford, UK, 1993).

[18] A. Damásio, The Feeling of What Happens: Body and Emotion in the Making of Consciousness, (Harcourt Brace, New York, NY, 1999).

[19] R.M. Davinson, Cultural Complications of ERP: Valuable Lessons Learned from Implementation Experiences in Parts of the World with Different Cultural Heritages, Communications of the ACM 45:7 (2002) 109-111.

[20] A.M. Davis and P. Hsia, Giving Voice to Requirements, IEEE Software 11:2 (March 1994) 12-16.

[21] A.M. Davis, Software Requirements: Analysis and Specification, (Prentice-Hall, Englewood Cliffs, NJ, 1990).

[22] G.W. Dickson and G. DeSanctis, Information Technology and the Future Enterprise: New Models for Managers, (Prentice-Hall, Englewood Cliffs, NJ, 2000).

[23] A. Dix, J. Finlay, G. Abowd, and R. Beale, Human-Computer Interaction, (Prentice-Hall, New York, NY, 1993).

[24] S.M. Easterbrook, SCW: Co-operation or Conflict?, (Springer, London, UK, 1992).

[25] S.M. Easterbrook and B. Nuseibeh, Using ViewPoints for Inconsistency Management, Software Engineering Journal 11:1 (January 1996) 31-43.

[26] R. Espejo, W. Schuhmannn, M. Schwaninger, and U. Bilello, Organizational Transformation and Learning: A Cybernetic Approach to Management, (JosseyBass, Chichester, UK, 1996). 
[27] J. Esteves and J. Pastor, Enterprise Resource Planning Systems Research: An Annotated Bibliography, Communications of the Association for Information Systems 7:8 (August 2001) 1-51.

[28] A.C.W. Finkelstein, Report of the Inquiry Into The London Ambulance Service, Report to The Communications Directorate, South West Thames Regional Health Authority, Original ISBN No: 0905133706 (February 1993) (http://www.cs.ucl.ac.uk/staff/A.Finkelstein/las/lascase0.9.pdf).

[29] A.C.W. Finkelstein and J. Dowell, A Comedy of Errors: the London Ambulance Service Case Study, Proceedings of 8th International Workshop on Software Specification and Design, IWSSD-8 (1996) 2-4.

[30] A.C.W. Finkelstein and M. Shattock, CAPSA and its implementation Report to the Audit Committee and the Board of Scrutiny University of Cambridge, Cambridge University Reporter CXXXII:6 (2 November 2001) 153-208 (http://www.admin.cam.ac.uk/reporter/2001-02/weekly/5861/).

[31] D.C. Gause, User DRIVEN Design-The Luxury that has Become a Necessity, A Workshop in Full Life-Cycle Requirements Management, International Conference on Requirements Engineering (ICRE) 2000, Tutorial T7, Schaumberg, IL (23 June 2000)

[32] R.L. Glass, Computing Catastrophes, (Computing Trends, Seattle, WA, 1983).

[33] R.L. Glass, Software Runaways, (Prentice-Hall, Upper Saddle River, NJ, 1998).

[34] J.A. Goguen and M. Jirotka, Requirements Engineering: Social and Technical Issues, (Academic Press, London, UK, 1994).

[35] J.A. Goguen, Requirements Engineering as the Reconciliation of Technical and Social Issues, Technical Report, Computing Laboratory, Oxford University, Oxford, UK (1993) modified version later published as [36]

[36] J.A. Goguen, Requirements Engineering as the Reconciliation of Technical and Social Issues, In: J.A. Goguen and M. Jirotka, eds., Requirements Engineering: Social and Technical Issues, (Academic Press, London, UK, 1994) 165-199.

[37] J.A. Goguen, Towards a Social, Ethical Theory of Information, In: G. Bowke, L. Gasser, L. Star, W. Turner, eds., Social Science Research, Technical Systems and Cooperative Work, (Erlbaum, Mahwah, NJ, 1997) 27-56.

[38] J.A. Goguen and M. Jirotka, Requirements Engineering: Social and Technical Issues, (Academic Press, London, UK, 1994).

[39] J.A. Goguen and J.J. Tardo, An Introduction to OBJ: A Language for Writing and Testing Formal Algebraic Program Specifications, Proceedings of a Conference on Specifications of Reliable Software, Cambridge, MA (April 1979) 170-189.

[40] R. Greenwood and C.R. Hinings, Understanding Strategic Change: the Contribution of Archetypes, Academy of Management Journal 36:5 (1993) 1052-1081. 
[41] M. Hammer, Reengineering Work: Don't Automate, Obliterate, Harvard Business Review 68:4 (July-August 1990) 104-112.

[42] J.C. Heckler, Prevention of Youthful Crime: the Great Stumble Forward (Routledge Kegan \& Paul London, UK, 1979).

[43] R. Hirschheim, H.K. Klein, and K. Lyytinen, Information Systems Development and Data Modeling: Conceptual and Philosophical Foundations, (Cambridge University Press, Cambridge, UK, 1995).

[44] K. Holtzblatt and H. Beyer, Contextual Design, (Morgan Kaufman, San Francisco, CA, 1998).

[45] A. Holzinger, Rapid Prototyping for a Virtual Medical Campus Interface IEEE Software 21:1 (January/February 2004) 92-99.

[46] C. Huff, Gender, Software Design, and Occupational Equity, Inroads, SIGCSE Bulletin 34:2 (June 2002) 112-115.

[47] J. Iivari, R. Hirschheim, and H.K. Klein, A Paradigmatic Analysis Contrasting Information Systems Development Approaches and Methodologies, Information Systems Research 9:2 (1998) 164-193.

[48] T.D. Jick, Accelerating change for competitive advantage, Organizational Dynamics 24:1 (1995) 77-82.

[49] M.O. Jones, Studying Organizational Symbolism, (Sage, Thousand Oaks, CA, 1996).

[50] Y. Kafai and M. Resnick, Constructionism in Practice: designing, thinking, and learning in a digital world, (Erlbaum, Mahwah, NJ, 1996).

[51] P.G.W.

Keen, Information Systems and Organizational Change, Communications of the ACM 24 (1981) 24-33.

[52] G. Kotonya and I. Sommerville, Requirements Engineering, (John Wiley \& Sons, West Sussex, UK, 1998).

[53] J.P. Kotter, Leading Change, (Harvard Business School Press, Cambridge, MA, 1996).

[54] R.M. Kramer and M.A. Neale, Power and Influence in Organizations, (Sage, Thousand Oaks, CA, 1998).

[55] M. Krumbholz, J. Galliers, N. Coulianos, and N.A.M. Maiden, Implementing Enterprise Resource Planning Packages in Different Corporate and National Cultures, Journal of Information Technology 15 (2000) 267-279.

[56] M. Krumbholz and N.A.M. Maiden, The Implementing of ERP Packages in Different Organisational and National Cultures, Information Systems Journal 26:3 (2001) 185-204. 
[57] M.M. Lehman, Programs, Life Cycles, and Laws of Software Evolution, Proceedings of the IEEE 68:9 (September 1980) 1060-1076.

[58] Y.S. Lincoln and E.G. Guba, Competing Paradigms in Qualitative Research, In: N.K. Denzin and Y.S. Lincoln, eds., Handbook of Qualitative Research, (Sage, Thousand Oaks, CA, 1994) 105-117.

[59] Y.S. Lincoln and E.G. Guba, Paradigmatic Controversies, Contradictions, and Emerging Confluences, In: N.K. Denzin and Y.S. Lincoln, eds., Handbook of Qualitative Research, (Sage, Thousand Oaks, CA, 2000) 163-188.

[60] R. Lutz and C. Mikulski, On-Going Requirements Discovery in High-Integrity Systems, IEEE Software 21: 2 (2004) 19-25.

[61] K. Lyytinen, L. Mathiassen, and J. Ropponen, Attention Shaping and Software Risk-A Categorical Analysis of Four Classical Risk Management Approaches, Information Systems Research 9:3 (1998) 233-255.

[62] L.A. Macaulay, Requirements Engineering, (Springer, London, UK, 1996).

[63] R. Marion, The Edge of Organization: Chaos and Complexity Theories of Formal Social Systems, (Sage, Thousand Oaks, CA, 1999).

[64] M.L. Markus, Power, Politics and MIS Implementation, Communications of the ACM 26 (1983) 430-444.

[65] R. Martinson, What Works? - Questions and Answers About Prison Reform, Public Interest 35 (1974) 22-54.

[66] G. Morgan, Images of Organization, (Sage, Thousand Oaks, CA, 1997).

[67] B. Nuseibeh and S.M. Easterbrook, Requirements Engineering: A Roadmap, In: A.C.W. Finkelstein, ed., The Future of Software Engineering 2000, Limerick, Ireland (June 2000).

[68] D.A. Norman, Emotion and Design: Attractive Things Work Better, ACM Interactions 9:4 (2002) 36-42.

[69] I. Palmer and C. Hardy, Thinking about management, (Sage, Thousand Oaks, CA, 2000).

[70] S. Papert, Introduction, In: I. Harel, ed., Constructionist Learning, (MIT Media Laboratory, Cambridge, MA, 1990).

[71] S. Parker and T. Wall, Job and Work Design: Organizing Work to Promote Well-Being and Effectiveness, (Sage, Thousand Oaks, CA, 1998).

[72] A.S. Pentland, R. Fletcher, and A. Hasson, DakNet: Rethinking Connectivity in Developing Nations IEEE Computer 37:1 (January 2004) 78-83.

[73] J. Pfeffer and A. Leong, Resource Allocations in United Funds: Examination of Power and Dependence, Social Forces 55 (1977) 775-790.

[74] J. Pfeffer and G. Salancik, The External Control of Organizations: a Resource Dependence Perspective, (Harper \& Row, New York, NY, 1978). 
[75] K.G. Provan, J.M. Beyer, and C. Kruytbosch, Environmental linkages and power in resource-dependence relations between organizations, Administrative Science Quarterly 25 (1980) 200-225.

[76] I.M.P. Ramos, Aplica cões das Tecnologias de Informa cão que suportam as dimensões estrutural, social, política e simbólica do trabalho, Ph.D. Dissertation Departamento de Informática, Universidade do Minho, Guimarães, Portugal (2000).

[77] S. Robertson and J. Robertson, Mastering the Requirements Process, (AddisonWesley, Harlow, England, 1999).

[78] W.N. Robinson and V. Volkov, Supporting the Negotiation Life Cycle, Communications of the ACM 41 (1998) 95-102.

[79] I. Santos and J.Á. Carvalho, Computer-Based Systems that Support the Structural, Social, Political and Symbolic Dimensions of Work, Requirements Engineering Journal 3:2 (1998) 138-142.

[80] I. Santos and J.Á. Carvalho, Creating Work Realities Supported by ComputerBased Systems: A Constructionist Perspective, REFSQ'02: Eighth International Workshop on Requirements Engineering: Foundation for Software Quality, (910 September 2002).

[81] S. Schach, Object-Oriented and Classical Software Engineering, Fifth Edition, (McGraw-Hill, New York, NY, 2002).

[82] T.A. Schwandt, Three Epistemological Stances for Qualitative Inquiry: Interpretivism, Hermeneutics, and Social Constructionism, In: N.K. Denzin and Y.S. Lincoln, eds., Handbook of Qualitative Research, (Sage, Thousand Oaks, CA, 2000) 189-213.

[83] C. Sickenius de Souza, R.O. Prates, and S.D.J. Barbosa, Adopting Information Technology as a First Step in Design, Lessons Learned from Working with Brazilian Social Volunteers, ACM Interactions X:2 (March+April 2003) 72-79.

[84] J. Siddiqi and M.C. Shekaran, Requirements Engineering: The Emerging Wisdom, IEEE Software 9:2 (March 1996) 15-19.

[85] W.E. Snizek, Virtual Offices: Some Neglected Considerations, Communications of the ACM 38 (1995) 15-17.

[86] M.L. Smith and G.B. Glass, Meta-Analysis of Psychotherapy Outcome Studies, American Psychologist 32:9 (September 1977) 752-760.

[87] I. Sommerville and P. Sawyer, Requirements Engineering, A Good Practice Guide, (John Wiley \& Sons, Chichester, UK, 1997).

[88] P.E. Spector, Job Satisfaction: Application, Assessment, Causes, and Consequences, (Sage, Thousand Oaks, CA, 1997).

[89] J.A. Swan, S. Newell, and M. Robertson, The Illusion of Best Practice in Information Systems for Operations Management, European Journal of Information Systems 8 (1999) 284-293. 
[90] A. van Lamsweerde, Requirements Engineering in the Year 00: A Research Perspective, Proceedings of 22nd International Conference on Software Engineering, Limerick, Ireland (June 2000). 